cating serious depression of the nervous system; the gas rarely produces any of these effects, end if ever, only in a slight degree. In order to produce the full effect of the ether, it is customary to reduce the patient to a state of stupor ; the gas is capable of rendering the body entircly insensible to the pain of the most severe surgical operation, without putting the patient to sleep, or causing any stupor! We have often observed patients watch the progress of severe operations upon their own persons, with countenances as smiling and happy as if they were enjoying a delightful treat.

We firmly believe that the gas would have long since entirely superseded the use of the ether, had it not been for the trouble attending its preparation. We trust, however, that in future this slight inconvenience will not prevent the surgeon, who has the welfare of his patient at heart, from making use of the agent so manifestly superior in its effects.

The State Legislature of Connecticut, which has just closed its session, has, after a due consideration of the evidences, fully recognized Dr. Horace Wells, of Hartford, as the sole discoverer, and have passed him a vote of thanks for this great discovery, which consists, as the vote expresses it, in the use of " nitrous oxide gas or ether in surgical operations." Thus the question of priority is finally settled by legislative enactment. E. E. M ARCY, M.D.

Hartford, August 21, 1847.

\title{
CASES IN WHICH GREY HAIR REGAINED ITS NATURAL COLOR.
}

By Robert J. Graves, M.D., Dublin.

A FIELD officer in a distinguished regiment had served for many years in tropical climates; had undergone the fatigues of the Burmese and other subsequent campaigns in the East Indies, during which he contracted dysentery and fever, and various maladies peculiar to hot countries; and finally, after many years' service, was obliged to return to Ireland for the purpose of regaining his health. When he consulted me he was worn and emaciated, and complained much of dyspeptic and nervous symptoms, with a constant tendency to bowel complaint. He was then 48 years of age, and his hair had, during a few years preceding, become quite white ; while his forehead, parts of his clieeks, and back of the neck and shoulders, presented many large maculæ of a brown color, nearly as deep as the areola around the nipple of a pregnant woman. In the course of four years he visited me again, having during the interval remained with the depot of lis regiment in England, and gradually regained his health under the influence of regimen and his native air. On his second visit I scarcely recognized my former patient. He had become robust and healthy-looking, and the macule had altogether disappeared, while his hair had regained its original brown color; not a single grey hair remained. The hair is now soft and silky, and has continued of its natural color during the last two years; but it is remarkable that the whiskers have remained white. 
In the year 1837 I was called by Dr. Beauchamp to see a gentleman, nged 67, laboring under the then prevalent influenza. He was a strong, hirsute man, and his chest was covered with long white hair, which had been black in his youth. We blistered him on the chest, and when he recovered from the disease the hair on the part that had been blistered grew again, but was now quite black, and has continued so since. I need scarcely add, that he is very proud of this unexpected symptom of returning youth, and readily exhibits to the curious this portion of his chest.

In the year 1845, Mr. Daly, of Henry street, consulted me in the case of a robust shopkeeper, aged about 35 , who had a slight attack of apoplexy, followed by incomplete hemiplegia. As the disease exhibited a tendency to relapse, we judged it necessary to establish a permanent drain from the vertex, to which a blister the size of a crown-piece was applied, and the surface was nade to discharge for several months by means of Albespeyre's plaster. When his recovery was complete, the blistered part was allowed to heal. I should have remarked that this gentleman was perfectly bald on this forehead, vertex and temples, and the skin of the scalp was smooth and shining. A few weeks after the blister was healed, a growth of hair took place, in the form of a ring, encircling the blistered surface at the distance of two lines.

Miss M., affected for many years with tinea capitis and psorophthalmia. The hair on the vertex had become quite grey, and there were several bald spots in the neighborhood. She was recommended by Mr. Wilde to use the common gas-water as a lotion to her head. After a long-continued use of the remedy, the hair grew on the bald spots, and both it and that on all the affected parts recovered the natural color. This was the more remarkable, inasmuch as the parts of the head to which the remedy was not applied are still covered with grey hair. Mr. Wilde observed a similar restoration of the color of the hair from the use of Donovan's brown citrine ointment.

Mr. B., aged about 35, when first seen, six years ago, had hair of a greyish color, from the intermixture of black and white hairs, the latter in comparatively very small number. He complained that his hair had been getting grey and falling out for some time previous, which he ascribed to bad health, consequent on impaired digestion. Twelve months afterwards the grey hairs had entirely disappeared, his health and strength having, in the meantime, much improved, chiefly by travelling.

Mrs. —_, aged 35, had a very scvere attack of fever, after recovery from which her hair turned quite grey, and began to fall out. The head was then shaved, and the slaving was repeated several times, after which there was an abundant growth of hair of the original auburn color.

Dr. Stokes has communicated to me the following fact relative to the hair, and which forms a singular exception to what is usually observed in phthisis. A young lady, of fair complexion and dark bair, became consumptive, and her luxuriant hair rapidly fell and deteriorated, being replaced by a thin, woolly, coarse crop. The tubercular disease proceeded 
slowly, lasting about fourteen montlis. About six weeks before her death, a new crop of hair appeared, if possible more beautiful than her original hair, and grew with such unexampled rapidity, that at the period of her death she had a splendid head of hair. Physiologically it is deserving of remark, that though this young lady had considerably emaciated in her body and limbs, her face and features preserved all the rotundity and plumpness of beauty; the scalp, therefore, was, in all probability, by no means deficient in nourishment. The unexpected appearance of hair excited vain hopes in the breast of the poor patient and her friends, who could not be persuaded that this new product of life was but the forerunner of death.

A friend of mine, a practitioner of great experience, now residing in Athy, came to Dublin to consult me while this paper was in the press. He is 70 years old, and labors under various nervous symptoms, which commenced about two years ago, with hemicrania of the right side of the head, attended with a singular and exquisitely painful aflection of the right half of the scalp, which was as sore as possible to the touch, and each hair in it felt, as my friend expressed it, like a minute poniard implanted in the skin. Nothing could exceed his agony for four dlays and nights, during which he never closed an eye ; at last a minute pustule, that soon desiccated, appeared round each hair, and in a fow days his scalp got well. During the height of the disease the engaged half of the scalp was red, but not erysipelatous. As far as I can understand this remarkable and rare case, it must be considered as an acute inflammation of the bulbs of the hair :- -strange enough, it was not followed by a falling out of the hair.

Whatever opinion the reader may have formed as to the relative value of the various theories formed to account for the growth and color of the hair, it seems clear that some practical deductions follow from the foregoing facts. In the first place, it is evident that the growth and color of the hair may be most beneficially influenced by the application of stimulants to the skin; and it is more than probable that numerous cases of baldness and want of color would yield to such an application of stimulants, if we only knew how to proportion the quantity of stimulants to the exigencies of each individual case. There is here a difficulty, probably insuperable, but which still we should try to surmount. Certain it is that many popular remedies which enjoy a great reputation, contain a combination of oily and stimulating substances, such as castor oil, goose-grease and tincture of cantharides. This composition, with the addition of a little sweet-smelling essential oil, often exerts, in my opinion, a decidedly beneficial effect when rubbed into the roots of the hair by means of a piece of flannel. The quantity of the tincture of cantharides should not exceed $3 j$. to $z j$., and our object should be by each application to produce a slight evanescent redness while the skin remains anointed with oil. When it is believed to be essential to produce a rapid desquamation of the epidermis, short of vesication, I know no better means than painting over the surface with the tincture of iodine every third or fourth day. A good pomade for the hair consists of equal parts 
of castor oil and lard, with the addition of attar of roses, about eight drops to four ounces.

To many it may appear trifling and beneath the dignity of a practical physician to dwell so much on this topic; but in truth mankind have always attached much importance to this ornament of the human body ; and grey hairs and baldness are to many quite as appalling as real disense, or even death. This feeling is not confined to the moderns, for we find the poets and the moralists of antiquity abound in passages to the same effect. The physician who has witnessed the strange degradation of appearance which follows the shaving of the fernale head in fever, must acknowledge that the grief of the ancient widow who laid het tresses on the tomb of her deceased husband, had at least a greater show of poignancy than is exhibited by our modern ladies, who on these occasions partially conceal, but never destroy, this cherished ornament. And they are probably right, for the operation of natural causes renders the growth of hair slower than the decrease of sorrow. I was not aware of the great degree of beauty which the hair imparts, until Mr. Clibborn showed me, in the Royal Irish Academy, a skull of a Peruvian female, in which the bones of the face and forehead were as usual exposed, but the desiccated scalp still bore a luxuriant crop of flowing ringlets, which imparted no small degree of beauty even to this death's head. I may here mention, that I once attended a lady upwards of 80 years of age, who exhibited all the usual appearances of withered senility, but who had a magnificent head of coal-black hair. Contrary to what might be expected, she bitterly deplored the circumstance, for this emblem of youth was but ill assorted with every other external sign of old age. "Two years ago," said my patient, "my maid, in combing me, discovered a grey hair. I was overjoyed, and hoped that ochers would speedily follow, but none have appeared since." She was the only person who ever asked me for a receipt to turn the hair grey.

We are aware that the least highly-organized tissues are capable of being reproduced after being destroyed; now many facts have come under my notice which seem to authorize the conclusion, that when the original stock of bulbs has been destroyed in the scalp, a new stock is frequently manufactured by the powers of nature, and thus an entirely new crop of hair arises. It is well known that cases have occurred where supernumerary teeth have been produced; and, in the celebrated Countess of Desmond, it was asserted that when the adult set of teeth failed from old age, a rejuvenescence took place, and a third set of teeth appeared. I was always inclined to doubt the truth of this assertion, until my friend Dr. Curran related to me the following particulars respecting his great-grandmother, Mrs. Waterworth. She had always been a remarkably healthy woman, was extremely active in her habits, and died, apparently, of mere senility, aged 95 . When about 80 , her sight, which for fifteen years previously had been so weak as to prevent her reading, became so completely restored, that at the time of her death she could, without spectacles, thread the finest needle, and read without fatigue or dificulty the very smallest print; she about the same time got a com- 
pletely new set of teeth. The exact number of teeth that grew at this unusual period I have not been able to ascertain; but of the fact, as stated above, there can be no doubt. This rejuvenescence was not consequent on any change of place or habits, but it was accompanied by a very considerable increase of strength, which continued to the last. Dr. Curran has a very curious copy of Mr. Easton's valuable work on Longevity, in which the author has added in manuscript notes many interesting particulars respecting Mary How, of Mapleton, Derlyyshire, who at the age of 110, got several new teeth, whilst her hair resumed its former color; Peter Bryan, of Tynan, County Tyrone, who cut several teeth at the age of 117; Lady Angelique Domengieux de Sempe, of Nouiliac, in France, who got teeth at 90, and lived thirteen years afterwards; Margaret Melville, of Kelle, Fifeshire, who lived to 117, and got teeth at 100 ; Jolin Minniken, of Maryport, Cumberland, whose hair grew so abundantly in his old age, that twenty wigs were made of it between his 80th and 112 th year ; and many sinular instances, of nany of which Mr. Easton was limself cognizant. These cases are, perhaps, not more extraordinary than that the costal cartilages should not have been ossified in the case of Old Parr, who lived to 152 , a fact for which we have the authority of a committee of the Rayal Society (annong whom was the great Harvey) appointed to make the post-mortem exa. mination. As an example of somewhat similar exception to general rules, Dr. Curran permits me to mention the case of his friend, Dr. Harrison, now a practising physician in the Isle of Man, who grew one inch in stature between his 30th and 32d year.-Dublin Med. Jour.

\section{THE BOSTON MEDICAL AND SURGICAL JOURNAL.}

BOSTON, SEPTEMBER 1, 1847 .

Complaints of the Scason.-Dysenteric affections are very general at the North, as they always are nt the season of the coming in of new fruits; yet the number of deaths has been comparatively small, which gives reason to suppose that physicians, when seasonably consulted, have been successful in their prescriptions.

Ship fever, which in the month of June excited much alarm, has lost most of its terrors, since experience has demonstrated that it is not so very formidable as was at first apprehended, and that judicious medication, ac.companied by appropriate nursing, rarely fails of being successful. It is when patients have undergone a long course of suffering at sea, sustained upon miserable food, and wedged in the hold of a vessel for woeks together, breathing and re-breathing the contaminated atmosphere of a kind of ma. rine prison, that the system gives way to the attacks of ship fever. Tho paper by Dr. Leonard, on this subject, in to-day's Journal, will be read with interest and advantage. 